\title{
The Relationship between Structural Transformation of Manufacturing Industry and Economic Growth in Liaoning Province
}

\author{
Tianshuai Xu ${ }^{\text {a }}$, Shuomin Zhao ${ }^{\text {b }}$, Shuai Zhu ${ }^{\mathrm{c}}$, Wanhong $\mathrm{Li}^{\mathrm{d}}$ \\ Harbin Engineering University, Harbin, 150001, China. \\ axvts@foxmail.com, bzhaosm0912@126.com, c15210829065@163.com, dliwanhong@hrbeu.edu.cn
}

Keywords: Manufacturing industry, economic growth, and top growth rate.

\begin{abstract}
The main purpose of this paper is to study the relationship between the transformation and upgrading of manufacturing industry and economic growth in the process of economic development. In modern economy, the transformation and upgrading of manufacturing industry is an important factor affecting economic growth, and it also has a very close relationship with economic growth. There is certain periodicity in the transformation and upgrading of manufacturing industry, which makes the relationship more clear, that is, when the transformation and upgrading of the manufacturing industry is vigorous, usually the economic growth will be faster. The transformation and upgrading of manufacturing industry can promote economic growth. The essence of economic growth is a process to continuously expand the industry with economic potential, constantly form new industries and transform and upgrade traditional industries, while the share of traditional industries in the total industry tends to decline. Because the growth rates of different industries are different, the change of status between low and high growth industries will affect economic growth.
\end{abstract}

\section{Introduction}

Under the implementation of the Strategy to Revitalize the Old Industrial Bases in Northeast China, the northeast region has met with rare opportunities for development after nearly ten years of rapid development. However, since the economy has entered the new normal, the economy of the three provinces of the Northeast China has declined again. In recent years, the economic growth of three provinces is obviously lower than the national average, and the economy is again in trouble, leading to the "new northeast phenomenon". The reason, which causes the phenomenon, is the accumulation and superposition of the traditional problems and the problems under the new normal, mainly in the aspects of institutional problems, structural contradictions and the slowdown of industrial structure upgrading. When facing these problems, it is urgent to study how to change the way of economic development. Structural reform and solving structural contradictions are the main directions to change the mode of economic development, and the transformation of industrial structure is the center of economic restructuring.

The old industrial base in Northeast China has made a historic contribution to the construction of China's industrial system and the development of the national economy. However, the economic growth in Northeast China has been stuck in growth predicament in the past few years; especially the "cliff decline" in the 2014 economic growth has aroused the high attention and concern of the government and scholars on the "new northeast phenomenon". The unbalance of the structure of the manufacturing industry in the old northeast industrial base is one of the main reasons, and the success of the transformation is the most important way to solve the problem of "new northeast phenomenon". It is necessary to investigate and study the economic development of Liaoning, as one of the three northeastern provinces, after transformation.

\section{The Impact of the Transformation and Upgrading of Manufacturing Industry on Economic Growth}

First of all, it can be understood that the transformation and upgrading of the manufacturing industry has a promoting effect on economic growth. The essence of economic growth is to 
continuously expand the potential industries in the economy, form new industries and transform and upgrade traditional industries, while the share of the traditional industries tends to decline over the total industry. Because the growth rates of different industries are not the same, the change of status between low and high growth industries will affect economic growth.

First, reconfigure the growth rates of different industries to promote economic growth. The growth rates of 29 subdivided industries in the manufacturing industry are different. The transformation and upgrading of the manufacturing industry makes the economic resources change between industries with different growth rates. The low growth rate usually develops to the high growth rate. Therefore, it has promoted the economic growth. Economic growth is the constant upgrading of traditional industries, the continuous formation of new industries and the growth of potential industries. Because the growth rates of industries are different, the change of status between low growth industries and high growth industries will affect economic growth.

Second, increase TFP to promote intensive economic growth. The core of the transformation and upgrading of manufacturing industry is the improvement of total factor productivity. The transformation and upgrading of manufacturing industry leads to the transfer of capital and labor factors from low productivity industries to high productivity industries, thus promoting economic growth. If the extensive growth model is to increase the factor input to achieve the economic growth, the economic growth will be achieved by increasing the factor efficiency in the intensive growth model. Therefore, the transformation and upgrading of manufacturing industry has not only the effect of growth, but also the effect of intensive growth.

Third, the replacement of leading industries is the main force of economic growth. Economic growth begins with the recovery, $R \& D$ and use of new technology in a certain industry. Through the "forward and backward correlation of industry", this advanced industry and its related industries are linked together to form a leading industry system. When the related industries in the national economy are affected by the advanced technology in the leading industry in the manufacturing industry, and the leading industry loses its advantages in technology and the advantage of labor productivity, the old leading industry will be replaced by the new leading industry with more advanced technology, thus promoting faster growth of the economy. Therefore, the process of transformation and upgrading of new and old leading industries has promoted economic growth.

\section{Theoretical Bases}

This chapter is an empirical study on the relationship between transformation and upgrading of manufacturing industry and economic growth in Liaoning province. Mainly from the following two aspects:

Theta Angle of Industrial Transformation. Through the calculation of the theta angle of the industrial transformation, the direction of the transformation and upgrading of the manufacturing industry and the measurement of the strength of the transformation are examined in order to reveal the relationship between the transformation and upgrading of the manufacturing industry and the economic growth.

Solow Residual Method. Through Solow residual method, the relationship between the transformation and upgrading of manufacturing industry and the quality of economic growth can be examined. The Solow residual method is usually based on the contribution of TFP (total factor productivity) growth rate to economic growth as a standard of evaluation, which if the contribution of TFP to economic growth increases, the quality of economic growth is rising constantly; otherwise, the quality of economic growth will reduce.

\subsection{The Correlation between the Transformation of Manufacturing Industry and Economic Growth.}

The first step is to calculate the impact and relationship of industry transformation and economic growth. The method of this paper is to first confirm the indexes of industrial transformation and economic growth, and then verify the relationship between industrial transformation and economic growth by comparing the alterable relation of the two variables. 
To measure the index of industrial transformation, Professor Deng Weigen of Jinan University adopted the method of vector angle in the article "industrial transformation and economic growth" which is coauthored with his students. This index has certain maneuverability, and it can also fully reflect the change range and the average transformation speed of industrial structure transformation. This paper continues to use the method of vector angle.

$$
\theta=\arccos \left[\sum_{i=1}^{n} S_{i}\left(t_{1}\right) S_{i}\left(t_{2}\right) / \sqrt{\sum_{i=1}^{n} S_{i}\left(t_{1}\right)^{2} S_{i}\left(t_{2}\right)^{2}}\right.
$$

In the formula 3.1, $\mathrm{N}$ is the number of industrial sectors, and $\mathrm{Si}(\mathrm{T})$ refers to the share of GDP in $\mathrm{t}$ year's total output value of I industry sector, and theta is the angle between the two vectors of S (T1) and $\mathrm{S}$ (T2), which can be considered as the industrial transition coefficient within the time period [t1, t2]. The greater the value of theta, the greater the degree of industrial transformation, the faster the transformation speed is in the same period, and the maximum value of theta is 90 degrees.

In order to get the value of $\mathrm{N}$ in the formula 1 , we need to re-classify the 29 industries that are subdivided within the manufacturing industry.

There are generally several ways to re-classify manufacturing industries:

(a) Consumption goods - Light industry - Heavy industry - Capital goods

(b) Traditional manufacturing industry - New manufacturing industry, high technology manufacturing industry

(c) Light industry, heavy industry - High processing industry - Knowledge-intensive industry

(d) Labor-intensive industry - Capital- intensive industry - Technology- intensive industry Knowledge- intensive industry

(e) Raw material - Initial processing manufacturing industry - Intensive processing manufacturing industry

Compared with the other several, the method D can better classify the 29 manufacturing industries. In addition, it can reflect the properties of the internal transformation and upgrading of the manufacturing industry according to the elements of labor, capital, technology and other elements. Therefore, this paper uses fourth methods, and the value of $\mathrm{N}$ is 4 .

Definitions of the four categories of industries are as follows:

Labor-intensive industry: Based on general consumption goods, its basic industries include food, wine, beverages and refined tea, tobacco, textile, clothing, clothing, leather, fur, feather-related products and footwear, wood processing and wood, bamboo, rattan, palm, grass, furniture, paper making and paper products, printing and recording media reproduction industry, culture, education, work beauty, sports and entertainment products.

Capital- intensive industry: Based on raw materials industry, its basic industries include petroleum processing, coking and nuclear fuel, chemical raw materials and chemical products, medicine, chemical fiber, rubber and plastics, non-metallic minerals, ferrous metal smelting and calendaring, metal products, waste gas recovery.

Technology- intensive industry: characterized by deep processing and high added value, its basic industries include general equipment, special equipment, transportation equipment, electrical machinery and equipment.

Knowledge- intensive industry: characterized by knowledge and technology, its basic industries include computers, telecommunications and other electronic devices, instrumentation.

\subsection{The Influence of the Transformation of Manufacturing Industry on the Growth of Sectorial Economy.}

After determining the relationship between the transformation and upgrading of the manufacturing industry and the economic growth, how much is the impact of the four major main industries on economic growth? Is the impact of the increase or reduction of the four major industries on the economic growth consistent? This needs to be calculated and answered.

In his article "industrial structure and economic growth", Professor Liu Wei of Peking University has constructed the function of the impact of industrial structure on production:

$$
Y=F\left(X_{1}, X_{2}, \ldots, X_{k}, A\right)
$$


In the formula, Y represents the total output; Xi represents the output of the I industry; A represents the economic system and technological level. In order to measure the contribution of changes in the proportion of industries to economic growth, the author makes complete differential of the function and further deforms it, and the formula is as follow:

$$
\frac{\mathrm{dY}}{\mathrm{Y}}=\frac{\mathrm{X} 1}{\mathrm{Y}} \frac{\partial \mathrm{Y}}{\partial \mathrm{X}_{1}} \frac{\mathrm{dX} 1}{\mathrm{X} 1}+\frac{\mathrm{X}_{2}}{\mathrm{Y}} \frac{\partial \mathrm{Y}}{\partial \mathrm{X}_{2}} \frac{\mathrm{dX} 2}{\mathrm{X}_{2}}+\cdots+\frac{\mathrm{Xk}}{\mathrm{Y}} \frac{\partial \mathrm{Y}}{\partial \mathrm{Xk}} \frac{\mathrm{dXk}}{\mathrm{Xk}}+\frac{\mathrm{A}}{\mathrm{Y}} \frac{\partial \mathrm{Y}}{\partial \mathrm{A}} \frac{\mathrm{dA}}{\mathrm{A}}
$$

To make $\beta \mathrm{i}=\frac{\mathrm{Xi}}{\mathrm{Y}} \frac{\partial \mathrm{Y}}{\partial \mathrm{Xi}}$ indicate the total output elasticity of the $\mathrm{I}$ industry, and then $\beta 0=\frac{\mathrm{A}}{\mathrm{Y}} \frac{\partial \mathrm{Y}}{\partial \mathrm{A}} \frac{\mathrm{dA}}{\mathrm{A}}$ indicates the contribution of economic institutional change to total output, so the above formula can be rewritten as follows:

$$
\frac{\mathrm{dY}}{\mathrm{Y}}=\beta_{1} \frac{\mathrm{dX} 1}{\mathrm{X} 1}+\beta_{2} \frac{\mathrm{dX} 2}{\mathrm{X} 2}+\cdots+\beta_{\mathrm{k}} \frac{\mathrm{dXk}}{\mathrm{Xk}}+\beta_{0} \frac{\mathrm{dA}}{\mathrm{A}}
$$

Taking the logarithm of both sides of the equation, we can get a quantitative model of the contribution of structural transformation to economic growth:

$$
\ln Y=\beta_{0}+\beta_{1} \ln X_{1}+\beta_{2} \ln X_{2}+\cdots+\beta_{k} \ln X_{k}+\varepsilon
$$

The model is simple and practical, and has good economic explanation function and maneuverability. Therefore, this section selects this model to measure the contribution of sector transformation to economic growth.

In the formula 2, Y represents the gross output value of the manufacturing industry, and the Xi represents the total output of each industry in the manufacturing industry. The significance of the $\mathrm{K}$ value is to consider the division of the internal structure of the manufacturing industry and to consider the interpretation effect of the measurement model. The value of the manufacturing industry mentioned above is determined to be 4 , that is, labor intensive industry - capital intensive industry technology intensive industry - knowledge intensive industry.

\subsection{The influence of the Transformation of Manufacturing Industry on the Quality of Economic Growth.}

If the economic growth pattern is classified according to the way of using elements, it can be roughly divided into two types: extensive growth and intensive growth. Extensive growth refers to the economic growth achieved by increasing the total amount of factor input, while intensive growth is the economic growth mainly through increasing the efficiency of essential factor utilization.

For the measure of the way of economic growth, that is, the intensive degree of economic growth, it is more popular in the world to take the contribution of the TFP growth rate to the economic growth as the evaluation standard. If the contribution of the TFP growth rate to economic growth increases, the intensification degree of the economic growth mode is increased; otherwise, it indicates that the degree of extensive growth is aggravated.

Therefore, this paper will first measure the contribution of total factor productivity to regional economic growth in Northeast China for many years, and then compare the sequential condition of contribution to the transformation of manufacturing industry in Northeast China. If there is a clear positive correlation between the two, it shows that the transformation of manufacturing industry has a significant effect in promoting the economic growth mode to intensive transformation.

The calculation method of TFP growth rate is commonly used Solow residual value method, which is:

\section{TFP growth rate $=$ GDP growth rate $-\alpha \times$ labor input growth rate $-\beta \times$ growth rate of investment}

In the formula, $\alpha$ is the coefficient of elasticity of labor, and $\beta$ is the coefficient of elasticity of capital.

In order to calculate the value of $\alpha$ and $\beta$, the $C D$ production function $G=A(T) K \alpha L \beta$ is used in this paper. Among them, G, K and L are GDP, capital and labor input respectively. A (T) is a production efficiency function under certain economic and technological conditions. It is a function of time $\mathrm{T}$, 
and generally the formula can be A $(\mathrm{T})=$ Eat. Since the change of scale efficiency can be embodied in the efficiency function $A(T)$, it is assumed that $\alpha+\beta=1$. Therefore,

$$
G=A e^{\gamma T} K^{\alpha} L^{1-\alpha}
$$

Both sides of the upper form are divided by $\mathrm{L}$ and then the logarithm is obtained:

$$
\ln \left(\frac{G}{L}\right)=\ln \mathrm{A}+\gamma \mathrm{T}+\alpha \ln \left(\frac{\mathrm{K}}{\mathrm{L}}\right)
$$

The upper model can be used to measure the TFP growth rate in Northeast China.

\section{Empirical Study on the Structural Transformation and Economic Growth of Liaoning's Manufacturing Industry}

\subsection{The Correlation between the Transformation and Upgrading of Manufacturing Industry and Economic Growth.}

Referring to the statistical yearbook of Liaoning Province, the changes of four major industrial structures in Liaoning manufacturing industry are calculated in the following table.

\begin{tabular}{|c|c|c|c|c|c|}
\hline \multirow[b]{2}{*}{ Year } & \multicolumn{4}{|c|}{ Structural Proportion (\%) } & \multirow[b]{2}{*}{$\begin{array}{l}\text { Total Output } \\
\text { (Million) }\end{array}$} \\
\hline & $\begin{array}{l}\text { Labor-intensive } \\
\text { Industry }\end{array}$ & $\begin{array}{l}\text { Capital-intensiv } \\
\text { e Industry }\end{array}$ & $\begin{array}{c}\text { Technology-intensiv } \\
\text { e Industry }\end{array}$ & $\begin{array}{c}\text { Knowledge-intensiv } \\
\text { e Industry }\end{array}$ & \\
\hline 1992 & 14.87 & 59.64 & 18.75 & 6.75 & 2010.82 \\
\hline 1996 & 17.75 & 55.33 & 22.66 & 4.27 & 3157.69 \\
\hline 2000 & 14.43 & 57.97 & 19.94 & 7.27 & 4669.06 \\
\hline 2004 & 13.31 & 58.98 & 23.04 & 6.05 & 6672 \\
\hline 2008 & 12.66 & 57.33 & 24.63 & 5.38 & 13668.58 \\
\hline 2012 & 11.79 & 54.38 & 30.73 & 3.11 & 24846.43 \\
\hline
\end{tabular}

Table 1. Changes in the structural proportion of four major industries in Liaoning in

Resource: Annual statistical yearbook of Liaoning

According to the change of the proportion of four main industries in the total output value of manufacturing industry in Liaoning Province, we can use formula 3.1 to calculate the coefficient of the transformation and upgrading coefficient of manufacturing industry, and then examine the relationship between the index of transformation and upgrading and the economic growth index.

Table 2. the relationship between the transformation of manufacturing industry and economic growth in Liaoning

\begin{tabular}{cccccc}
\hline Time Period & $1992-1996$ & $1996-2000$ & $2000-2004$ & $2004-2008$ & $2008-2012$ \\
\hline Transformation Coefficient (Degree) & 6.31 & 5.16 & 7.18 & 9.54 & 7.82 \\
Economic Growth Rate & 0.57 & 0.48 & 0.32 & 1.05 & 0.82 \\
Average Annual Transformation & 1.58 & 1.29 & 1.8 & 2.39 & 1.96 \\
$\quad$ Coefficient & & & 0.07 & 0.19 & 0.16 \\
$\begin{array}{c}\text { Average Annual Economic Growth } \\
\text { Rate }\end{array}$ & 0.12 & 0.11 & & \\
\hline
\end{tabular}

Based on the data of tables 1 and 2, the following conclusions can be drawn about the relationship between the transformation of manufacturing industry and the growth of sectoral economic volume in Liaoning.

First, the transformation and upgrading of manufacturing industry has a positive correlation with the economic growth of Liaoning province. The transformation and upgrading path of "labor intensive - capital intensive - technology intensive - knowledge intensive" can significantly promote economic growth in Liaoning province. When the industrial transformation coefficient is improved, it shows that the manufacturing industry is rapidly changing to the technology intensive industry and the knowledge intensive industry, and the share of the two is increased in the total output value of the manufacturing industry. The knowledge intensive industry generally has higher marginal contribution of factors than the technology intensive industry, labor intensive industries, and capital intensive industry. As a result, the rate of economic growth will increase; otherwise, the rate of economic growth will decline.

Second, the transformation and upgrading of manufacturing industry has a certain periodicity and a certain overlap with the periodicity of industrial policy, which reveals the possible impact of 
industrial policy on economic growth in the short term. In 1992 - 1996 and 2004 - 2008, the transformation rate of manufacturing industry in Liaoning is relatively fast, which is closely related to the industrial development policy issued by the state and local governments. With the passage of time, the continuous release of industrial policy forces and the disappearance of industrial policy advantages, the efforts to promote industrial transformation and upgrading of policies tend to decrease, and the upgrading of industrial transformation has slowed down.

\subsection{The Influence of the Transformation of Manufacturing Industry on the Growth of Sectorial Economics.}

Referring to the statistical yearbook of Liaoning Province, the logarithm value of the four industries is made in the following table.

Table 3 data operation table of Liaoning province manufacturing industry contribution model

\begin{tabular}{cccccc}
\hline Year & $\begin{array}{c}\text { The output of } \\
\text { Manufacturing Industry }\end{array}$ & $\begin{array}{c}\text { Labor } \\
\text { Intensive }\end{array}$ & $\begin{array}{c}\text { Capital } \\
\text { Intensive }\end{array}$ & $\begin{array}{c}\text { Technology } \\
\text { Intensive }\end{array}$ & $\begin{array}{c}\text { Knowledge } \\
\text { Intensive }\end{array}$ \\
\hline 2000 & $\ln Y$ & $\operatorname{lnX1}$ & $\operatorname{lnX2}$ & $\operatorname{lnX3}$ & $\ln 4$ \\
\hline 2001 & 3.554 & 2.728 & 3.321 & 2.852 & 2.414 \\
2002 & 3.582 & 2.728 & 3.344 & 2.904 & 2.431 \\
2003 & 3.621 & 2.779 & 3.369 & 2.883 & 2.518 \\
2004 & 3.727 & 2.849 & 3.481 & 3.085 & 2.584 \\
2005 & 3.866 & 2.984 & 3.631 & 3.222 & 2.641 \\
2006 & 3.991 & 3.136 & 3.752 & 3.35 & 2.731 \\
2007 & 4.12 & 3.289 & 3.874 & 3.49 & 2.828 \\
2008 & 4.249 & 3.434 & 3.993 & 3.634 & 2.942 \\
2009 & 4.325 & 3.569 & 4.055 & 3.71 & 2.965 \\
2010 & 4.439 & 3.695 & 4.162 & 3.844 & 2.998 \\
2011 & 4.547 & 3.844 & 4.274 & 3.925 & 3.033 \\
2012 & 4.594 & 3.895 & 4.31 & 3.994 & 3.044 \\
2013 & 4.64 & 3.955 & 4.328 & 4.022 & 3.086 \\
\hline
\end{tabular}

According to the data provided in table 4.3 and the use of Eviews5.0 measurement software, we can get the following economic regression model of the relationship between transformation and upgrading of manufacturing industry and economic growth in Liaoning Province:

The regression equation can be obtained from the upper form:

$$
\begin{array}{lll}
\ln Y=0.6542+0.3143 \ln \mathrm{X}_{1}+0.3644 \ln \mathrm{X}_{2}+0.2158 \ln X_{3}+0.0941 \ln X_{4} \\
(5.6648)
\end{array}
$$

The coefficient of determination in the above equation is $\mathrm{R} 2=0.9998$, and the coefficient of determination after adjusting is $\mathrm{R} 2(\mathrm{ad})=0.9997$, which means Labor intensive, capital intensive, technology intensive and knowledge intensive industries have an overall explanatory significance for the economic growth of the manufacturing industry. The D-W statistic $=1.0144$ shows that there is no sequence correlation in the residuals of regression equation in 9. Therefore, from the statistical sense, the parameter estimation of the equation is believable.

Based on the above regression equation, we can make further judgement on the relationship between the transformation and upgrading of manufacturing industry and economic growth in Liaoning.

First, labor intensive and capital intensive industries have contributed significantly to the growth of manufacturing in Liaoning in the past 14 years. When labor intensive industries increase by $1 \%$, the economy can increase by $0.3143 \%$; if capital intensive industries increase by $1 \%$, the economy will grow by $0.3644 \%$. It is foreseeable that in the short term, labor intensive and capital intensive will still be an important driving force for Liaoning's economic growth.

Second, the contribution of highly processed industries such as general equipment manufacturing and transportation equipment to the overall economic growth of Liaoning's manufacturing sector is in the second place. After 2000, the output of the technology intensive industry increases by $1 \%$, which can promote the growth of the total output value of manufacturing industry by $0.2158 \%$. It can be foreseen that the transformation of Liaoning's manufacturing industry to the highly processed 
industry will be accelerated, which will help to maintain the rapid and stable growth of Liaoning's economy.

Third, the knowledge intensive industry dominated by computer, communication and other electronic equipment manufacturing industry has little contribution to the economic growth of Liaoning Province, and it is still in its infancy. The total output value of the knowledge-based industry increases by $1 \%$, and the total economic growth of the manufacturing industry is only $0.0659 \%$. In recent years, Liaoning's computer, telecommunications and other electronic equipment manufacturing industry has increased rapidly, with an annual growth rate of $15 \%$. However, from the perspective of relative size, the share of manufacturing, including computers, telecommunications and other electronic equipment manufacturing, is still small. In 2013, the proportion of computer, communications and other electronic equipment manufacturing was the largest, but it was only $3.5 \%$ of the total manufacturing value, and the average level of the country was about $10 \%$ in the same period. There is still a big gap between Liaoning's knowledge-based industry and the whole country.

This section shows that the transformation and upgrading of manufacturing industry in Liaoning is closely related to economic growth. Labor intensive and capital intensive plays an important role in promoting the economic growth of Liaoning province. The effect of high processing industry on the economic growth of manufacturing industry is great, which leads to the transformation of high processing industry. It is beneficial to accelerate the rapid growth of manufacturing industry in Liaoning province.

At present, the knowledge intensive industry based on computer, communication and other electronic equipment manufacturing industry has less impetus to the economic growth of Liaoning Province, but compared with other industries, the factor efficiency and the resource allocation effect of the knowledge industry are great, which can promote the transformation of the growth mode of manufacturing industry in Liaoning Province.

\subsection{The Influence of the Transformation of Manufacturing Industry on the Quality of Economic Growth.}

In order to facilitate comparative analysis, this paper will be divided into two stages, which are 2000-2006 and 2007-2013. For example, table 4 is the 2000-2013 year GDP data on fixed assets investment and labor input.

Table 4. GDP investments in fixed assets and labor input in Liaoning province from 2000 to 2013

\begin{tabular}{ccccccc}
\hline Year & $\begin{array}{c}\text { Gross output value of the } \\
\text { manufacturing industry } \\
\text { (hundred million yuan) }\end{array}$ & $\begin{array}{c}\text { K (hundred } \\
\text { million } \\
\text { yuan) }\end{array}$ & $\begin{array}{c}\text { L (ten thousand } \\
\text { people) }\end{array}$ & $\begin{array}{c}\ln \\
(\mathrm{K} / \mathrm{L})\end{array}$ & $\mathrm{T}$ & $\begin{array}{c}\text { ln } \\
(\mathrm{G} / \mathrm{L})\end{array}$ \\
\hline 2000 & 2114.89 & 398.67 & 78.98 & 10.83 & 1 & 12.5 \\
2001 & 2190.12 & 421.41 & 85.47 & 10.81 & 2 & 12.45 \\
2002 & 2331.95 & 469.33 & 99.51 & 10.76 & 3 & 12.36 \\
2003 & 2556.82 & 573.65 & 103.8 & 10.92 & 4 & 12.41 \\
2004 & 2680.41 & 940.45 & 113.25 & 11.33 & 5 & 12.37 \\
2005 & 3401.8 & 1563.97 & 122.7 & 11.76 & 6 & 12.53 \\
2006 & 4017.02 & 2078.74 & 128.49 & 11.99 & 7 & 12.65 \\
2007 & 4892.45 & 2832.75 & 121.33 & 12.36 & 8 & 12.91 \\
2008 & 6359.43 & 3916.94 & 142.62 & 12.52 & 9 & 13.01 \\
2009 & 6925.63 & 4632.78 & 142.62 & 12.69 & 10 & 13.09 \\
2010 & 8789.27 & 5839.6 & 149.85 & 12.87 & 11 & 13.28 \\
2011 & 10696.54 & 5976.44 & 154.99 & 12.86 & 12 & 13.44 \\
2012 & 11605.07 & 7493.08 & 151.1 & 13.11 & 13 & 13.55 \\
2013 & 12510.27 & 8632.1 & 144.65 & 13.3 & 14 & 13.67 \\
\hline
\end{tabular}

First, GDP, fixed assets investment and labor input data in $2000-2006$ are used for regression analysis. The following regression equation can be obtained:

$$
\begin{aligned}
& \ln \left(\frac{G}{L}\right)=15.16455+0.177048 \mathrm{~T}+0.299126 \ln \left(\frac{\mathrm{K}}{\mathrm{L}}\right) \\
& \mathrm{R} 2=0.992982 ; \mathrm{F}=282.9662
\end{aligned}
$$


The 2000-2006 year production function can be obtained by restoring the upper form to:

$$
G=3853722 e^{0.177048 T} K^{0.299126} L^{0.700874}
$$

The following is GDP regression analysis of fixed assets investment and labor input data in 2007 2013.The following regression equation can be obtained:

$$
\ln \left(\frac{G}{L}\right)=8.549205+0.056479 \mathrm{~T}+0.369987 \ln \left(\frac{\mathrm{K}}{\mathrm{L}}\right)
$$

$\mathrm{R} 2=0.964485 ; \mathrm{F}=6.492027$

The production function in $2007-2013$ can be obtained by restoring the upper form to:

$$
G=5162 e^{-0.056479 T} K^{0.369987} L^{0.630013}
$$

Through the comparison of the production function of 2000-2006 years and the production function of 2007-2013 years, it is found that the labor input in Liaoning province is reduced, but the input of labor is still large. The investment of capital is less and the scale of capital is smaller. In the 2000-2006 year, the contribution of labor growth rate and the growth rate of TFP to the growth rate of GDP is great, and the contribution of the growth rate of fixed assets investment is very small, which is mainly due to the heavy industrial industry in Liaoning province. In the 2007-2013 years, the contribution of fixed asset investment growth and the contribution of TFP growth rate rose sharply. This is mainly due to the vigorous development of capital intensive industries in Liaoning province.

The effect of manufacturing industry transformation on the quality of economic growth (7), formula (8), formula (10) and formula (12) respectively calculated the TFP growth rate and its contribution to economic growth in 2000-2006 and 2006-2013 years in Liaoning province and its contribution to economic growth (table 5).

The section make use of formula 7 , formula 8 , formula 10 and formula 12 calculate the TFP growth rate and its contribution to economic growth in 2 periods of 2000-2006 and 2006-2013 years in Liaoning province (table 5).

Table 5. Liaoning's fixed assets investment, labor input, TFP growth rate and contribution and transformation coefficient

\begin{tabular}{ccccccccc} 
Year & $\begin{array}{c}\text { Growt } \\
\text { h rate } \\
\text { of G }\end{array}$ & $\begin{array}{c}\text { Growth } \\
\text { rate of } \\
\text { K }\end{array}$ & $\begin{array}{c}\text { Growth } \\
\text { rate of } \\
\text { L }\end{array}$ & $\begin{array}{c}\text { Growth } \\
\text { rate of } \\
\text { TFP }\end{array}$ & $\begin{array}{c}\text { The growth } \\
\text { contribution } \\
\text { rate of K }\end{array}$ & $\begin{array}{c}\text { The growth } \\
\text { contribution } \\
\text { rate of L }\end{array}$ & $\begin{array}{c}\text { The growth } \\
\text { contribution } \\
\text { rate of TFP }\end{array}$ & $\begin{array}{c}\text { Annual } \\
\text { transformation }\end{array}$ \\
\hline $2000-2006$ & 0.1128 & 0.3168 & 0.0845 & 0.0587 & 0.1076 & 0.484 & 0.5336 & 0.3429 \\
$2007-2013$ & 0.1694 & 0.2041 & 0.0297 & 0.0975 & 0.3604 & 0.1229 & 0.5756 & 1.053 \\
\hline
\end{tabular}

It can be seen from table 5 that since 2000, the contribution of labor and capital to economic growth is inversely proportional to the contribution of TFP to the growth rate and the annual transformation. The contribution of labor and capital to economic growth is gradually decreasing. The TFP growth rate in Liaoning province and its contribution to economic growth are positively related to the transformation and upgrading coefficient of production industry. It shows that the transformation of economic growth has a significant impact on the quality of economic growth, that is, if the speed of the transformation and upgrading of the manufacturing industry is accelerated, the quality of economic growth is improved; and the quality of economic growth is reduced if the speed of the transformation and upgrading of the manufacturing industry tends to slow.

\section{Conclusion}

The main purpose of this paper is to study the relationship between the transformation and upgrading of manufacturing industry and economic growth in the process of economic growth. In modern economy, the transformation and upgrading of manufacturing industry is an important factor affecting economic growth, and the transformation and upgrading of manufacturing industry has a very close relationship with economic growth.

First, there are certain periodicity in the transformation and upgrading of manufacturing industry. This periodicity makes the relationship between the transformation and upgrading of manufacturing industry and the economic growth more clear. If there is greater transformation and upgrading of the manufacturing industry, it usually indicates a faster economic growth. 
Second, through the calculation of the $\theta$ angle model of the industrial transformation, it is found that the transformation and upgrading of the manufacturing industry itself has periodicity in certain length of time, and it is closely related to the policy periodicity of our country. This periodicity reveals the great influence of industrial policy on the practice of regional economic transformation in the short term. In the first half of 2000-2008, the transformation and upgrading trend of manufacturing industry is great, while the trend in 2008-2013 is slowed down, which means the trend of transformation is related to the main industrial development policies at national level. With the passage of time, the constant release of the policy force and the flattening of the policy advantage, the power of policy to the industrial transformation is decreasing, and the strength of industrial transformation slows down.

Third, through the construction of the quantitative relationship table between the industrial transformation angle and the economic growth rate, it is found that the transformation and upgrading of the manufacturing industry in Liaoning province is highly related to the economic growth. The greater the transformation and upgrading of the manufacturing industry, the faster the economic growth will be and GDP growth rate or economic growth rate will rise. When the transformation intensity is reduced, the GDP growth rate or economic growth rate will decline. There is a strong positive correlation between the transformation and upgrading of manufacturing industry and the rate of economic growth. Labor intensive and capital intensive are the main contributors to the growth of manufacturing industry in Liaoning province. When labor intensive industries increase by $1 \%$, the economy can increase by 0.3143 ; if capital intensive industries increase by $1 \%$, the economy will grow by 0.3644 . The contribution of technology intensive industries, such as general equipment manufacturing, special equipment manufacturing, transportation equipment and so on, is the second place in promoting the overall economic growth of Liaoning manufacturing industry. After 2000, the output of the technology intensive industry increases by $1 \%$, which can promote the increase of $0.2158 \%$ of the total output value of the manufacturing industry. It can be foreseen that the transformation of Liaoning's manufacturing industry to the technology intensive industry will be accelerated, which will help to maintain the rapid and stable growth of the economy of Liaoning province.

Fourth, the growth effect of the transformation and upgrading of manufacturing industry, on the one hand, will affect the speed of economic growth, and on the other hand, it will also affect the transformation of the mode of economic growth. The growth rate of TFP in Liaoning province and its contribution to economic growth have a positive correlation with the industrial transformation coefficient, that is, the speed of industrial transformation is accelerating, and the quality of economic growth has been improved. The growth effect of industrial transformation is to improve the quality of economic growth, and also to transform the economy to intensive growth mode. The process of industrial transformation is also the process of reconfiguration of various production factors in different industrial departments. The production factors shift from the lower productivity sector to the higher productivity sector, which can improve the total factor productivity of the society itself. At the same time, because the factor flow has improved the production linkages and coordination among various departments, total factor productivity will also be improved.

Fifth, the transformation and upgrading of manufacturing industry and economic growth have mutual promotion and restriction with each other, but the effect of the two is not completely released in the current period. As far as Liaoning is concerned, there is a lagging relationship between the transformation and upgrading of manufacturing industry and economic growth. The promotion and restriction effect of the transformation and upgrading of manufacturing industry on economic growth is not completely released in the current period. There may be some delay between the two. The possible economic growth is very fast, while the transformation and upgrading of the manufacturing industry is slow; the transformation and upgrading of the manufacturing industry in Liaoning is fast, while the rate of economic growth may be relatively slow. By now, the economic growth of Liaoning province has not been significantly affected. 


\section{Acknowledgments}

This research was supported by funding from the Philosophy \& Social Science Project of Heilongjiang Province (NO.16JYB04) and the National College Students' innovative training program (NO. 201810217096).

\section{References}

[1]. Social innovation and mega cities: what are the opportunities for business? [J]. Anonymous. Civil Engineering: Magazine of the South African Institution of Civil Engineering. 2015 (1).

[2]. Chen Zheng'gao. Report on the Work of the Government. At the Second Session of the Twelfth Liaoning People's Congress, Shenyang, 2014.

[3]. Wang Yueping. Theory, Practice and Policy of Industrial Structure Adjustment and Upgrading in China. Beijing: China Planning Publishing House, 2001.

[4]. Song Wei, GU Guozhang. An Examination of the Path of China's Manufacturing Industry Upgrading. Commercial Age, 2009, (18):103-104.

[5]. Zhao Wencheng, Zhao Hong. Research on Competitive Strategy of China's Manufacturing Industry Based on Industrial Value Chain. Chinese Engineering Science, 2008,10 (9): 245-246

[6]. The decomposition of productivity gap between Estonia and Korea. Sepp J, Warplane U. Discourses in Social Market Economy. 2014. 